\title{
Scanning electron microscopic examination of the nasal mucosa epithelium in atrophic rhinitis
}

\author{
H. Hamdi Çelik ${ }^{1}$, Mustafa F. Sargon ${ }^{1}$, M. Bülent Özdemir ${ }^{2}$, Faruk Ünal ${ }^{3}$, Metin Önerci ${ }^{3}$ \\ ${ }^{1}$ Department of Anatomy, Faculty of Medicine, Hacettepe University, Ankara, Turkey \\ ${ }^{2}$ Department of Anatomy, Faculty of Medicine, Pamukkale University, Denizli, Turkey \\ ${ }^{3}$ Department of Otorhinolaryngology, Faculty of Medicine, Hacettepe University, Ankara, Turkey
}

\begin{abstract}
Objective: In this study, we aimed to examine the ultrastructural characteristics of nasal mucosa in patients with atrophic rhinitis and reported our findings.

Methods: The biopsy specimens were obtained from two children and three adult patients, who had some or all of the classical manifestations of atrophic rhinitis. The tissue samples were prepared according to routine histological scanning electron microscopic tissue preparation procedure and examined using scanning electron microscope. The study was carried out in the electron microscopy laboratory of the Anatomy Department of Hacettepe University, Ankara, Turkey, between February 2001 and March 2003.

Results: Squamous epithelium showing keratinization was observed in large areas. Additionally, desquamation of the horny cells of the nasal mucosa epithelium was found. The findings obtained in this study were in accordance with preview studies. Besides all these, we also observed accumulation of bacteria, especially the cocci in some focal regions. This accumulation of the bacteria may play a very important role in the etiology of the disease.

Conclusion: Depending upon to the difficulty of finding patients with atrophic rhinitis, even the few number of cases observed in this study will have an importance for the ultrastructural characteristics of the disease.
\end{abstract}

Key words: nasal mucosa; atrophic rhinitis; ultrastructure; scanning electron microscopy

Anatomy 2008; 2: 34-38, @ 2008 TSACA

\section{Introduction}

Atrophic rhinitis is a chronic disease in which an atrophic and sclerotic mucous membrane, abnormal patency of the nasal cavities, crust formation and foul odor are present. ${ }^{1,2}$ The mucous membrane changes from ciliated pseudo stratified columnar epithelium to stratified squamous epithelium, and the lamina propria is reduced in amount and vascularity. Anosmia results and epistaxis may be recurrent and severe. The etiology is unknown. However, bacterial infections may play a role in this disease.
In this study, we aimed to obtain the ultrastructural changes observed in atrophic rhinitis. Depending upon to the very low incidence of atrophic rhinitis, these findings will have a great importance in the description of the pathological changes, observed in this disease.

\section{Materials and Methods}

The biopsy specimens were obtained from two children and three adult patients. All of the adult patients were male and their ages were 28,42 and 54 years. The 
children were three and five years old and both of them were male as well. The patients taking part in this study had some, or all of the classical manifestations of atrophic rhinitis; crusting, foul smell, epistaxis and sensation of nasal obstruction.

The tissue samples were fixed in $2.5 \%$ glutaraldehyde for 24 hours, washed in phosphate buffer (pH: 7.4), postfixed in $1 \%$ osmium tetroxide for one hour, washed in phosphate buffer ( $\mathrm{pH}: 7.4)$, dehydrated in increasing concentrations of acetone, critical point dried and mounted on metal stubs with a double sided adhesive band. Then, the samples were sputtered with a 100 Angstrom thick layer of gold in a BIO-RAD (England) sputter apparatus. Their photographs were taken with a Jeol SEM-ASID 10 (Japan) scanning electron microscope. ${ }^{8}$

\section{Results}

The surface topography of the epithelium was revealed in considerable details with the scanning electron microscope, which also gave a striking three-dimensional appearance. In the examination of the tissue samples taken from patients with atrophic rhinitis, abnormalities and irregularities were observed in the nasal mucosa. At higher magnifications, these abnormalities were found to be the result of desquamation of the horny cells, especially observed in the anterior part of the nasal cavity (Figures 1 and 2). Depending upon to the desquamation, large areas which were devoid of nasal mucosa epithelial cells were found (Figure 2). Additionally, the surface structures of the atrophic mucosa were much
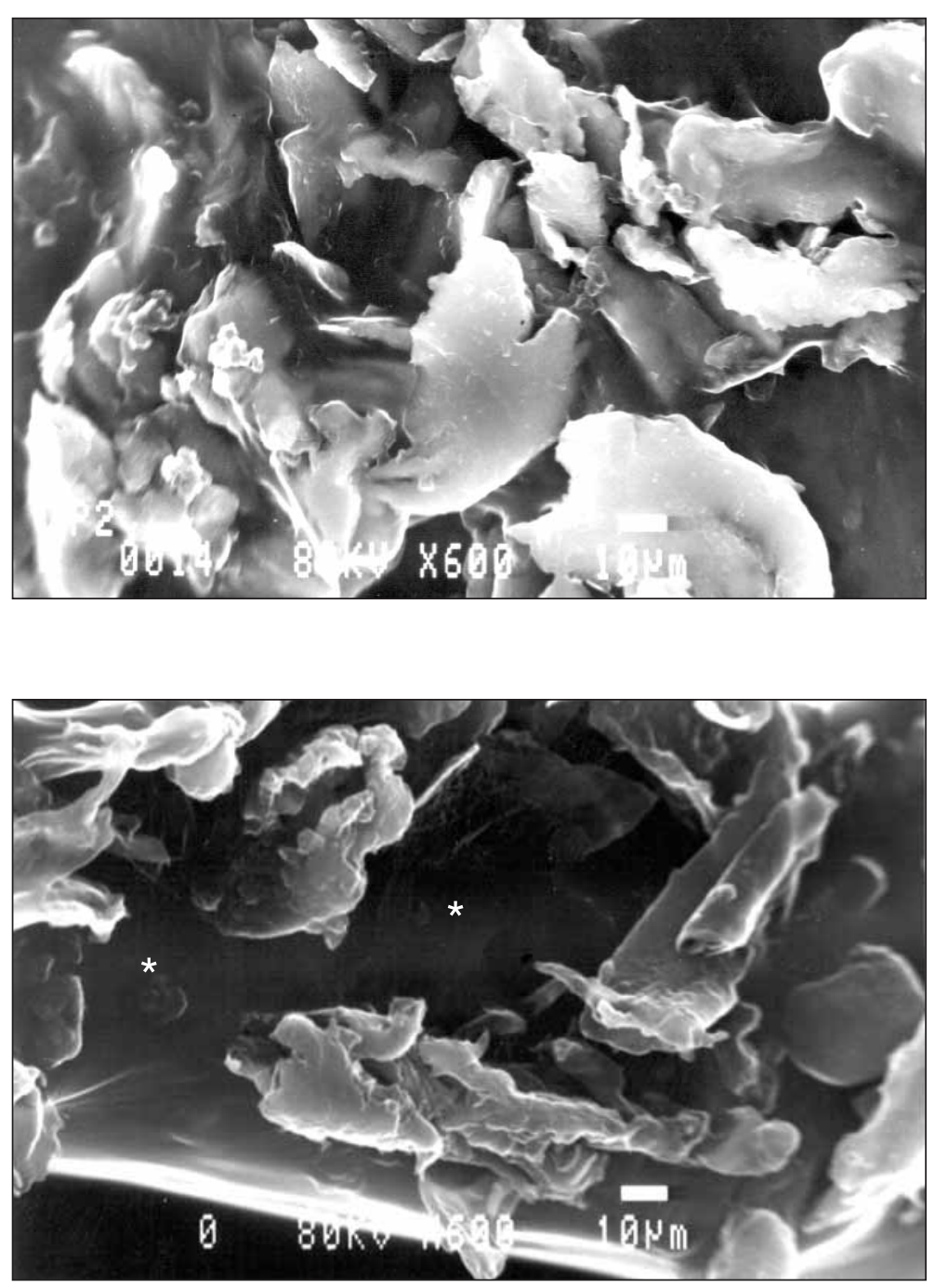

Figure 1. Abnormal desquamation of horny cells (Original magnification $\times 600$ ).

Figure 2. Abnormal desquamation of horny cells (Original magnification $\times 600)$. *: Large areas which were devoid of nasal mucosa epithelial cells. 
shorter and more scattered than in the normal mucosa (Figure 3) and microvilli were not seen in the squamous epithelium of the nasal mucosa (Figures 3, 4 and 5). In most of the examined areas, bacteries were found and most of them were cocci (Figure 6).

\section{Discussion}

The first study, related with atrophic rhinitis was performed by Holopainen in 1967. ' In this light microscopic study, the author observed keratinized squamous epithelium. These were located as islands and showed different localizations. These findings were in accordance with our results. Mygind et al., Barton et al. and Gray et al. examined the scanning electron microscopic findings in atrophic rhinitis. ${ }^{10-12}$ They also showed desquamations in the nasal mucosa. Microvillous like projections were found to be shorter and more scattered than the microvilli and cilia. In our study, in addition to all these findings, we also observed accumulation of bacteries, especially the cocci in some focal regions. This accumulation of the bacteries may play a very important role in the etiology of the disease. ${ }^{3-7}$ In a radiologic study, Pace-Balzan et al. described and discussed the CT findings with clinical evidence of atrophic rhinitis. ${ }^{13}$

The decrease in the surface area of atrophic mucosa renders its capability of holding moisture, resulting in a severely impaired ability to resist dehydration. Long standing atrophic rhinitis may produce a saddle nose

Figure 3. Surface structures are shorter and more scattered in atrophic mucosa (Original magnification x600).

Figure 4. Abnormal desquamation of horny cells forming irregular, dome-like appearances (Original magnification $\times 500)$.
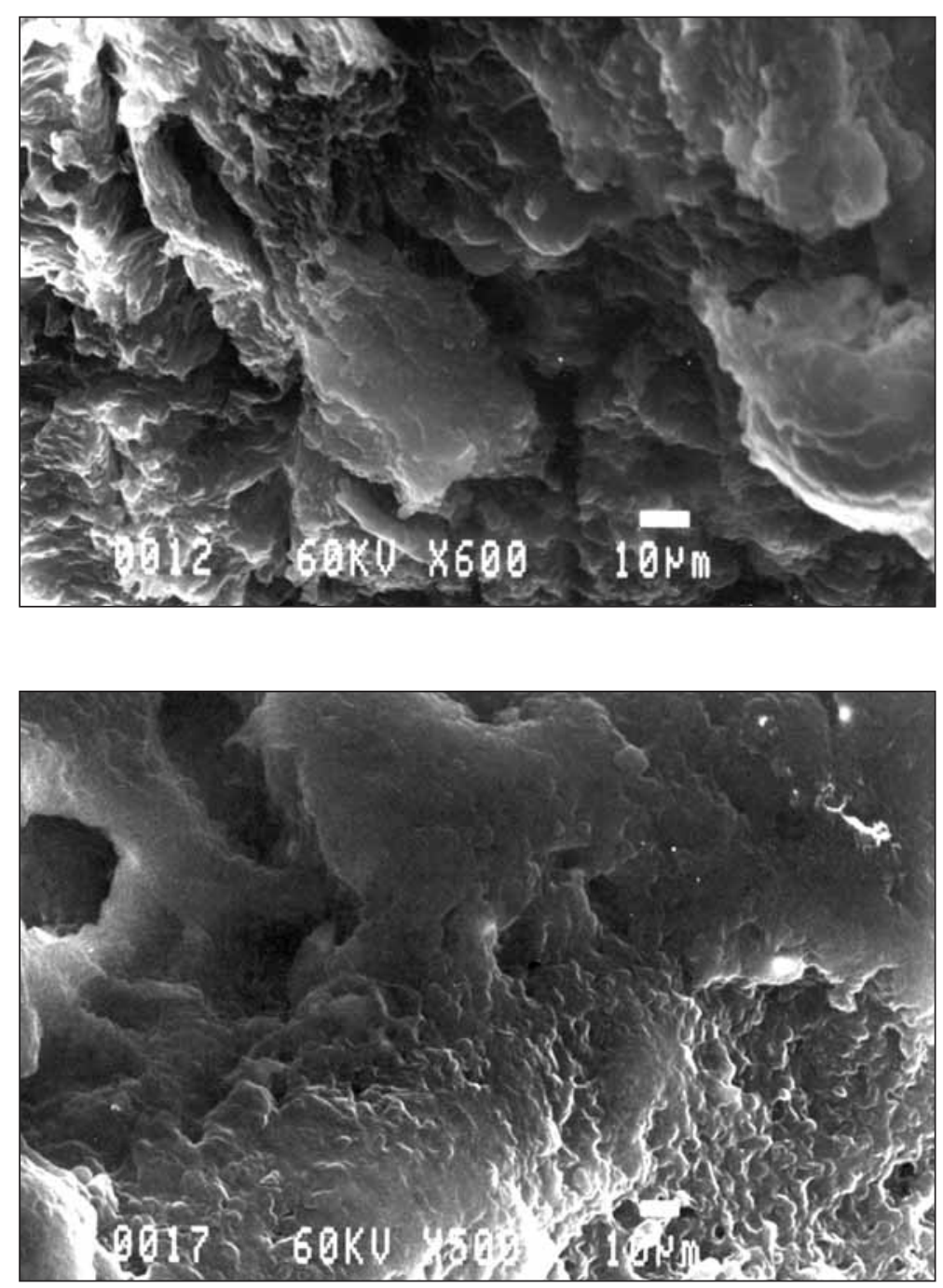

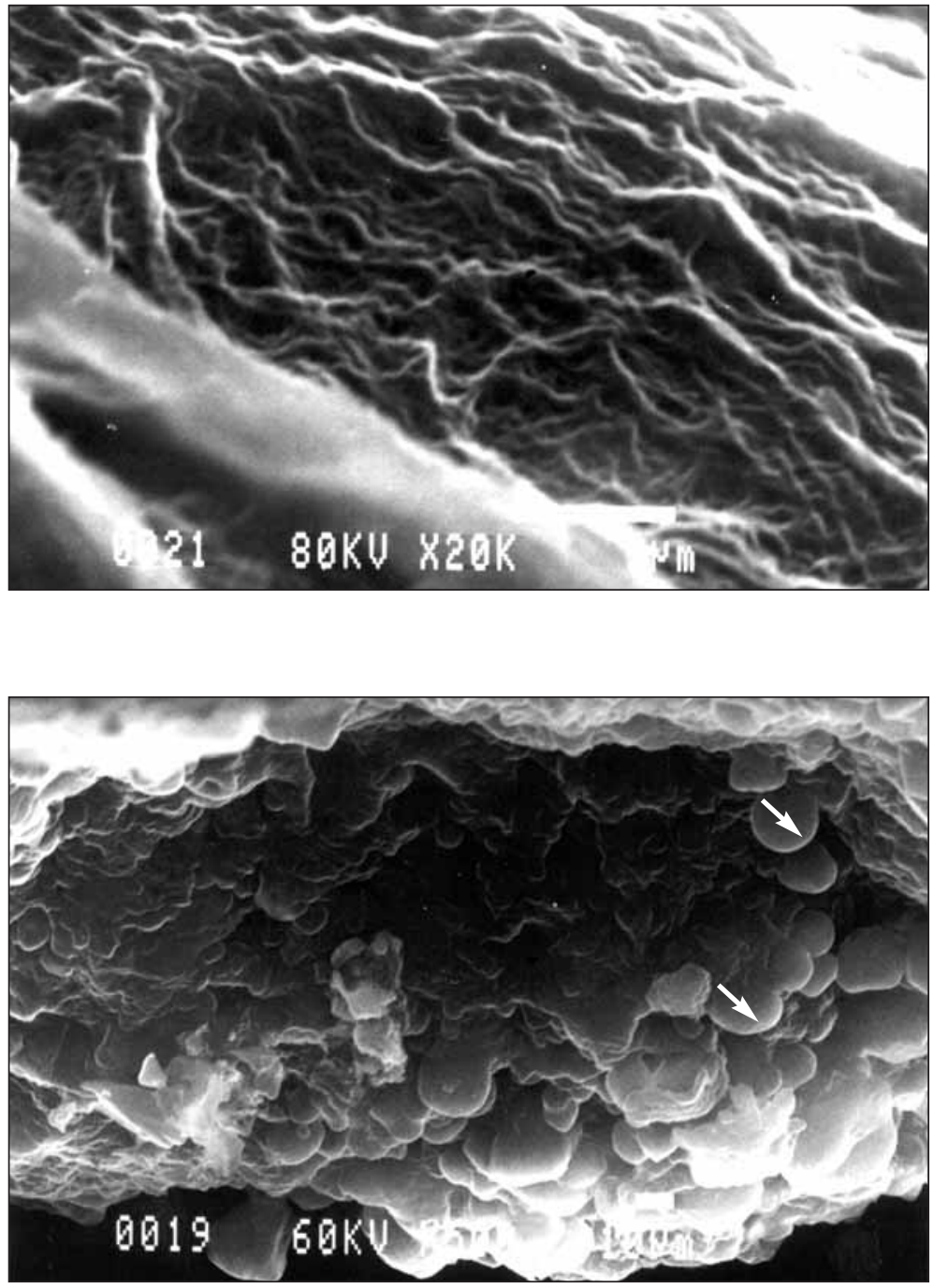

Figure 5. Surface of the atrophic mucous membrane (Original magnification $\times 20000$ ). The surface structures of the cells are scattered and short, microvillous like projections are present.
Figure 6. Surface of the atrophic mucous membrane. In most of the examined areas, bacteries (arrow) are seen (Original magnification $\times 500$ ). deformity due to absorption of the nasal bones and septal cartilage as well. ${ }^{14}$

It seems obvious that any lesion preventing the formation or maturation of large numbers of motile cilia or the production of mucous capable of forming confluent sheets suitable for continuous propulsion, may cause atrophic rhinitis. In both familial and idiopathic forms of the disease, both abnormalities are present. Thus, it would be more interesting to know the ultrastructure of the ciliae in transverse sections by transmission electron microscopy. Transmission electron microscopic studies in retinitis pigmentosa, Usher's syndrome and Kartagener's syndrome now becoming known as the low cilia motility diseases show clearly the primary lesions in the micro-tubules and dynein arms of the cilia. A similar transmission electron microscopic study in atrophic rhinitis may show the fundamental clial lesions. ${ }^{12}$

Although many therapeutic measures have been tried for atrophic rhinitis, none of them has proved to be wholly successful. ${ }^{2,15-18}$

We know that atrophic rhinitis is a disease with mucosal atrophy and decrease in secretion. In addition to clinical observations, there are some microscopic findings that we have mentioned above. Thus the findings obtained in this study were in accordance with them. Besides all this, we also observed accumulation of bacteria, especially the cocci in some focal regions. This accumulation of the bacteria may play a very important role 
in the etiology of the disease. In conclusion, depending upon to the difficulty of finding patients with atrophic rhinitis, even the few number of cases observed in this study will have an importance for the ultrastructural characteristics of the disease.

\section{References}

1. Katırcıŏlu S, Karatay S, Erbengi T, Gürsoy E, Sunay T. Ultrastructural findings of the nasal mucosa of "ozaena" in atrophic rhinitis. Acta Otolaryngol 1979; 88: 432-7.

2. Fanous N, Baxter JD. Silastic implant in atrophic rhinitis- a rewiev of 10 cases. 7 Otolaryngol 1978; 7: 541-4.

3. Pijoan C, Trigo F. Bacterial adhesion to mucosal surfaces with special reference to Pasteurella multocida isolates from atrophic rhinitis. Can 7 Vet Res 1990; 54: 16-21.

4. Ferguson JL, Mc Caffrey TV, Kern EB, Martin WJ. Effect of Klebsiella ozaenae on ciliary activity in vitro: implications in the pathogenesis of atrophic rhinitis. Otolaryngol Head Neck Surg 1990; 102: 207-11.

5. Nakai T, Kume K, Yoshikawa H, Oyamada T, Yoshikawa T. Changes in the nasal mucosa of spesific-pathogen-free neonatal pigs infected with Pasteurella multocida or Bordetella bronchiseptica. Nippon fuigaku Zasshi 1986; 48: 693-701.

6. Gagne S, Martineau-Doize B. Nasal epithelial changes induced in piglets by acetic acid and by Bordetella bronchiseptica. 7 Comp Pathol 1993; 109: 71-81.

7. Ackermann MR, Cheville NF, Gallagher JE. Colonization of the pharyngeal tonsil and respiratory tract of the gnotobiotic pig by a toxigenic strain of Pasteurella multocida type D. Vet Pathol 1991; 28: 267-74.
8. Çelik HH, Aldur MM, Özdemir B, İlgi S. The usage of scanning electron microscope in microscopic anatomy. 7 Morph 2001; 9: 3942.

9. Holopainen E. Nasal mucous membrane in atrophic rhinitis with reference to symptomfree nasal mucosa. Histology, histochemistry and exfoliative cytology. Acta Otolaryngol 1967; Suppl 227: 1-55.

10. Mygind N, Thomsen J, Jorgensen MB. Ultrastucture of the epithelium in atrophic rhinitis. Acta Otolaryngol 1974; 77: 439-46.

11. Barton RP, Gray RF, Wright JL, Dilly PN. Familial atrophic rhinitis: a scanning electron microscopic study. 7 Laryngol Otol 1980; 94: 993-6.

12. Gray RF, Barton RP, Wright JL, Dilly PN, Moss RF. Primary atrophic rhinitis: a scanning electron microscopic (SEM) study. $\mathcal{Z}$ Laryngol Otol 1980; 94: 985-92.

13. Pace-Balzan A, Shankar L, Hawke M. Computed tomographic findings in atrophic rhinitis. 7 Otolaryngol 1991; 20: 428-32.

14. Baser B, Grewal DS, Hiranandani NL. Management of saddle nose deformity in atrophic rhinitis. F Laryngol Otol 1990; 104: 4047.

15. Girgis IH. Surgical treatment of ozena by dermofat graft. $\mathcal{7}$ Laryngol Otol 1966; 80: 615-27.

16. Shehata M, Dogheim Y. Surgical treatment of primary chronic atrophic rhinitis (an evaluation of silastic implants). 7 Laryngol Otol 1986; 100: 803-7.

17. Gupta SC. Septoplasty in unilateral atrophic rhinitis with deviated nasal septum. 7 Laryngol Otol 1985; 99: 163-5.

18. Zakrzewski A, Topilko A, Zakrzewski J. Nasal mucosa in the iron deficient state. A clinical and electron-microscopic study. Acta Otolaryngol 1975; 79: 176-9.

Correspondence to: $\mathrm{H}$. Hamdi Çelik, MD, PhD Department of Anatomy, Faculty of Medicine, Hacettepe University Ankara 06100 Turkey Phone: +90 31230523 56; Fax: +90 3123107169 e-mail: hhcelik@hacettepe.edu.tr Conflict of interest statement: No conflicts declared. 